\title{
EVALUATION OF INHALER USE TECHNIQUE IN A PEDIATRIC APPOINTMENT
}

\author{
Joana Cleto Duarte da Costa Ribeiro, Carolina dos Santos Folques Alves, Maria Manuel Zarcos. \\ Department of Pediatrics, Centro Hospitalar de Leiria, Leiria, Portugal.
}

\begin{abstract}
Introduction: Inhalers are recommended for asthma prophylactic and crisis therapy. In order to have a good deposition of drugs at pulmonary tissue, the correct use of the devices is necessary.

Objective: To verify the inhaler use technique with pressurized metered-dose inhalers (pMDIs) with spacers and dry-powder inhalers (DPIs) in a pediatric sample (ages between 1 and 17 years old).

Material and Methods: Descriptive, observational and cross-sectional study. Application of a checklist that included the steps of the correct inhaler use technique, which was performed under physician observation, and other questions related to the use of the devices.
\end{abstract}

Results: We observed a total of 83 inhaler use techniques: 46 pMDIs with spacers and 37 DPIs. About 54\% of pMDIs with spacers users and $27 \%$ of DPIs users performed the inhaler use technique correctly, $p=0.012$. The most frequent mistakes in pMDIs with spacers users were: $50 \%$ didn't waste the first puff, $17.4 \%$ didn't shake the device prior to use and $28.3 \%$ didn't wait between inhalations. The mistakes observed in DPIs users were: $43.2 \%$ didn't perform a forced expiration before inhaler use, $13.5 \%$ didn't start with a forced inspiration, $24.3 \%$ didn't pause at the end of inspiration, $32.4 \%$ didn't exhale slowly and $35.1 \%$ didn 't wait between inhalations.

Conclusion: Multiple mistakes were observed even in the users who had been followed up for several years. The most frequent mistakes occurred in DPIs users. Thus, the inhaler use technique must always be observed by the physician in all appointments, especially in users of DPIs in which the correct use depends on their autonomy.

\section{Introduction}

Asthma is the most common chronic disease of childhood and is characterized by a chronic airway inflammation. ${ }^{1}$ It's a global health problem and its prevalence is increasing. ${ }^{1}$ Treatment goals are to achieve symptoms control, maintain normal activity levels and minimize risk of exacerbations or sequelae. ${ }^{1}$ Inhalation is the recommended route for both exacerbations and prophylactic therapy. ${ }^{1,2}$ There is a wide variety of devices available on the market with different inhaler use technique. ${ }^{3}$ The selection of the right inhaler must take into consideration the age of the child, inspiratory capacity and collaborative ability. ${ }^{1,4}$ It is very important that inhaled particles deposit in the lungs, and the only way to achieve it is with a correct inhaler use technique. ${ }^{5}$ The correct use of devices is associated with the control of asthma. 2,4,6 The incorrect use is associated with exacerbations, more use of systemic corticosteroids, more visits to the hospital,

Address for Correspondance: Joana Cleto Duarte da Costa Ribeiro, Rua da Figueira, n038, Ericeira. 2655431 Ericeira. Portugal.

Email: joana-ribeiro@campus.ul.pt

@2021 Pediatric Oncall

\section{ARTICLE HISTORY}

Received 30 September 2021

Accepted 29 November 2021

\section{KEYWORDS}

inhaler use, asthma, child

\section{ABBREVIATIONS:}

DPIs: Dry-powder inhalers; Fig: Figure; IQR: Interquartile range: pMDIs: Pressurized metered-dose inhalers. absences from school, reduction and limitation of sports activities. ${ }^{5}$

The aims of this study were to characterize and verify the inhaler use technique with pressurized metereddose inhalers (pMDIs) with spacers and dry-powder inhalers (DPIs).

\section{Methods \& Materials}

Descriptive, observational and cross-sectional study. We included all children (between 1 and 17 years old) who used inhaled therapy and were followed up in a pediatric appointment of our hospital, after their caregivers' consent. The duration period of the study was 2 months (October and November 2018). We observed the inhaler use technique using sample devices during pediatric consultation. We used a checklist, literature-based $>$ sup $>3,4$, to verify if all steps were correctly performed. To define a correct technique, we considered all the steps listed in table 1 and 3, except the waste of the first puff in pMDIs. Afterwards we made additional questions to the child and caregiver about issues related to the use of pMDIs with spacers and DPIs. The statistical analysis performed, using SPSS $22^{\circledR}$, was descriptive and bivariate, we used Chi-square and Fisher's exact test $(a=0.05)$. 


\section{Results}

We observed 83 inhaler use techniques from 81 inhaler device users (two of them used both the devices). The median age of the total sample was 8 years [Interquartile range (IQR) 8], 67.5\% were male. Pressurized metered-dose inhalers (pMDIs) with spacers were used by 46 (55\%) and dry-powder inhalers (DPIs) by 37 (45\%). A correct inhaler use technique was performed by $35(42.2 \%)$ : 25 (54.3\%) of pMDIs with spacer users and $10(27 \%)$ of PDIs users, $\mathrm{p}=0.012$ test (chi-square test).

Pressurized metered-dose inhalers with spacers $(n=46)$ Median age was 6 years (IQR 4 ) and $63 \%$ were male. Median age of first exacerbation was 1 year (IQR 1.5). Regarding other comorbidities: $15 \%$ had allergic rhinitis and $11 \%$ eczema. $41.3 \%$ had a family member with asthma of which $63.2 \%$ used pMDIs with spacer. Median of the time since the first appointment was 2 years (IQR 2.25). All of these children used salbutamol in crisis and $93.5 \%$ were on prophylactic therapy $(82.6 \%$ inhaled corticoid, $21.7 \%$ antileukotriene and $6.5 \%$ long-acting beta-agonists and corticoid ).

$54.3 \%$ performed a correct inhaler use technique of pMDIs with spacer users (Figure. 1): $55 \%$ of the group who had a follow-up period $<2$ years versus $53.8 \%$ of the group with a follow-up period $\geq 2$ years, $p=0.938$ (chi-square test); $47.4 \%$ of the group who had relatives with asthma versus $59.3 \%$ of the group which had no relatives with asthma, $\mathrm{p}=0.425$ (chi-square test).
Table 1 represent the results from the observation of inhaler use technique. All of them (100\%) removed the cover, placed pMDIs and mask correctly, with the child awake. Other three steps had a percentage higher than $90 \%$ : child was standing or sitting in $97.8 \%$, breathed slowly and deeply in $95 \%$, inhalation duration of 10 seconds in $95.7 \%$. Three steps had a percentage lower than $90 \%$ : they shook the pMDIs in $82.6 \%$, they wasted one puff into the "air" (in the first use or when they didn't use the pMDIs for a long time) in 50\% and they waited 30-60 seconds for the next inhalation in $71.1 \%$. Regarding the comparison between those whose follow-up was less than two years or 2 years or more and those who had or not relatives with asthma, there was no statistically significant difference.

Table 2 represent the results from questions made to caregivers. All of them (100\%) store the pMDIs correctly and $95.7 \%$ confirmed the expiration date. As for cleaning: $34.8 \%$ washed the spacer correctly and at the right frequency and $30.4 \%$ cleaned the mask after each use. Regarding the use of inhaled corticosteroids: $75.6 \%$ used bronchodilator before inhaled corticosteroids in crises and $87.8 \%$ rinsed the mouth and washed face after inhaled corticosteroids. About $76.1 \%$ took pMDIs to nursery/school in crises. Concerning the comparison between those whose follow-up was less than two years or 2 years or more and those who had relatives or not with asthma, there was no statistically significant difference.

Table 1. Results from the observation of inhaler use technique of pressurized metered-dose inhalers with spacers.

\begin{tabular}{|c|c|c|c|c|c|c|c|}
\hline & \multirow[b]{2}{*}{$\begin{array}{l}\text { Total } \\
(n=46)\end{array}$} & \multicolumn{3}{|c|}{ Follow-up time } & \multicolumn{3}{|c|}{ Family member with asthma } \\
\hline & & $\begin{array}{l}<2 \text { years } \\
(n=20)\end{array}$ & $\begin{array}{l}\geq 2 \text { years } \\
(n=26)\end{array}$ & $\begin{array}{l}\text { Chi-square/ } \\
\text { Fisher's } \\
\text { exact test }\end{array}$ & $\begin{array}{l}\text { Yes } \\
(n=19)\end{array}$ & $\begin{array}{l}\text { No } \\
(n=27)\end{array}$ & $\begin{array}{l}\text { Chi-square/ } \\
\text { Fisher's } \\
\text { exact test }\end{array}$ \\
\hline Shake the pMDIs & $82.6 \%$ & $80 \%$ & $84.6 \%$ & $p=0.713^{f}$ & $84.2 \%$ & $81.5 \%$ & $p=1.000^{f}$ \\
\hline Remove the cover & $100 \%$ & $100 \%$ & $100 \%$ & NA & $100 \%$ & $100 \%$ & NA \\
\hline $\begin{array}{l}\text { First use/didn't use it } \\
\text { for a long time, take an } \\
\text { inhalation into the "air" }\end{array}$ & $50 \%$ & $60 \%$ & $42.3 \%$ & $p=0.234$ & $47.4 \%$ & $51.9 \%$ & $p=9.765$ \\
\hline $\begin{array}{l}\text { Child is standing or } \\
\text { sitting }\end{array}$ & $97.8 \%$ & $100 \%$ & $96.2 \%$ & NA & $94.7 \%$ & $100 \%$ & NA \\
\hline Child is awake & $100 \%$ & $100 \%$ & $100 \%$ & NA & $100 \%$ & $100 \%$ & NA \\
\hline Place pMDIs correctly & $100 \%$ & $100 \%$ & $100 \%$ & NA & $100 \%$ & $100 \%$ & NA \\
\hline Put the mask correctly & $100 \%$ & $100 \%$ & $100 \%$ & NA & $100 \%$ & $100 \%$ & NA \\
\hline $\begin{array}{l}\text { Breathe slowly and } \\
\text { deeply (older child) } \\
(n=40)\end{array}$ & $95 \%$ & $100 \%$ & $92 \%$ & NA & $94.4 \%$ & $95.5 \%$ & $p=1.000^{f}$ \\
\hline Duration 10 seconds & $95.7 \%$ & $95 \%$ & $96.2 \%$ & $p=1.000^{f}$ & $94.7 \%$ & $96.3 \%$ & $p=1.000^{f}$ \\
\hline $\begin{array}{l}\text { Wait } 30-60 \text { seconds for } \\
\text { the next inhalation }\end{array}$ & $71.7 \%$ & $65 \%$ & $76.9 \%$ & $p=0.373$ & $63.2 \%$ & $77.8 \%$ & $p=0.278$ \\
\hline
\end{tabular}

Legend: ${ }^{f}$ - fisher's exact test, NA - non applicable, pMDIs - pressurized metered-dose inhalers. 
Table 2. Other questions made to the group that used pressurized metered-dose inhalers with spacers.

\begin{tabular}{|c|c|c|c|c|c|c|c|}
\hline & \multirow[b]{2}{*}{$\begin{array}{l}\text { Total } \\
(n=46)\end{array}$} & \multicolumn{3}{|c|}{ Follow-up time } & \multicolumn{3}{|c|}{ Family member with asthma } \\
\hline & & $\begin{array}{l}<2 \text { years } \\
(n=20)\end{array}$ & $\begin{array}{l}>2 \text { years } \\
(n=26)\end{array}$ & $\begin{array}{l}\text { Chi-square/ } \\
\text { Fisher's } \\
\text { exact test }\end{array}$ & $\begin{array}{l}\text { Yes } \\
(n=19)\end{array}$ & $\begin{array}{l}\text { No } \\
(n=27)\end{array}$ & $\begin{array}{l}\text { Chi-square/ } \\
\text { Fisher's } \\
\text { exact test }\end{array}$ \\
\hline Clean the mask after each use & $30.4 \%$ & $30 \%$ & $30.8 \%$ & $p=0.955$ & $21.1 \%$ & $37 \%$ & $p=0.246$ \\
\hline $\begin{array}{l}\text { Wash the spacer } 2 / 3 \text { times a } \\
\text { month correctly }\end{array}$ & $34.8 \%$ & $45 \%$ & $26.9 \%$ & $p=0.202$ & $31.6 \%$ & $37 \%$ & $p=0.702$ \\
\hline $\begin{array}{l}\text { Confirms the expiration date of } \\
\text { pMDIs }\end{array}$ & $95.7 \%$ & $95 \%$ & $96.2 \%$ & $p=1.000^{f}$ & $89.5 \%$ & $100 \%$ & NA \\
\hline $\begin{array}{l}\text { Store the device in a dry place } \\
\text { at a mild temperature }\end{array}$ & $100 \%$ & $100 \%$ & $100 \%$ & NA & $100 \%$ & $100 \%$ & NA \\
\hline $\begin{array}{l}\text { In crises, uses bronchodilators } \\
\text { before inhaled corticosteroids } \\
(n=41)\end{array}$ & $75.6 \%$ & $89.5 \%$ & $63.6 \%$ & $p=0.075$ & $76.5 \%$ & $75 \%$ & $p=1.000^{f}$ \\
\hline $\begin{array}{l}\text { After inhaled corticosteroids } \\
\text { rinses the mouth and washes } \\
\text { face }(n=41)\end{array}$ & $87.8 \%$ & $89.5 \%$ & $86.4 \%$ & $p=1.000^{f}$ & $82.4 \%$ & $91.7 \%$ & $p=0.633^{f}$ \\
\hline $\begin{array}{l}\text { In crises, take pMDIs to nurs- } \\
\text { ery/school }\end{array}$ & $76.1 \%$ & $80 \%$ & $72.1 \%$ & $p=0.732^{f}$ & $78.9 \%$ & $74.1 \%$ & $p=1.000^{f}$ \\
\hline
\end{tabular}

Legend: ${ }^{f}$ - fisher's exact test, NA - non applicable, pMDIs - pressurized metered-dose inhalers.

Figure 1. inhaler use technique in pressurized metered-dose inhalers with spacers users

$\begin{array}{lcc}\text { No relatives with asthma }(n=27) & 59.30 \% & 40.70 \% \\ \text { Relatives with asthama }(n=19) & 47.40 \% & 52.70 \% \\ \text { Follow-up period } \geq 2 \text { years }(n=26) & 53.80 \% & 46.20 \% \\ \text { Follow-up period }<2 \text { years }(n=20) & 55 \% & 45 \% \\ \text { Total }(n=46) & & \\ \end{array}$

Correct technique Incorrect technique

\section{Dry-powder inhalers $(n=37)$}

Median age was 13 years (IQR 2.5) and 73\% were male. Median age of first crisis was 3 years (IQR 5.5). Regarding other comorbidities: $29.7 \%$ had allergic rhinitis and $5.4 \%$ eczema. $35.1 \%$ had a family member with asthma and all of them used DPIs. Median of the time since the first appointment was 5 years (IQR 4). In crises, $89.2 \%$ used salbutamol and $10.8 \%$ terbutaline. Concerning the device, $75.7 \%$ used novolizer $§, 13.5 \%$ pMDIs (5.4\% with spacer) and $10.8 \%$ turbohaler $®$. All of them were on prophylactic therapy (40.5\% longacting beta-agonists and corticoid, $37.8 \%$ inhaled corticoid and $24.3 \%$ antileukotriene). As for the device $55.2 \%$ used diskus $\AA, 27.6 \%$ turbohaler $\AA, 13.8 \%$ pMDIs and $3.4 \%$ aerolizer $\circledR$.

Performed a correct inhaler use technique $27 \%$ of DPIs users (Figure. 2): $36.8 \%$ of the group who had a followup period $<2$ years versus $16.7 \%$ of the group who had a follow-up period $\geq 2$ years, $p=0.269$ (fisher's exact test); $23.1 \%$ of the group had relatives with asthma versus $29.2 \%$ of the group who had no relatives with asthma, $p=1.000$ (fisher's exact test).

Table 3 represent the results from the observation of inhaler use technique. All of them (100\%) placed the device correctly, while the child was standing or sitting. Of all steps considered, other two steps had a percentage higher than $90 \%$ : they prepared the dose in $94.6 \%$ and placed the mouthpiece correctly in $97.3 \%$. All the other steps were performed in under $90 \%$ of the cases: $56.8 \%$ performed a forced expiration, $86.5 \%$ inhaled deeply and quickly, $75.5 \%$ did the inspiratory pause, $67.6 \%$ expired slowly afterwards, $64.9 \%$ waited 30-60 seconds for the next inhalation. Regarding the comparison between the 2 groups of follow-ups and those who had or not relatives with asthma, there was no statistically significant difference.

Table 4 represent the results from questions that we made to the child and caregivers. All of them (100\%) store the DPIs correctly. Concerning expiration date, in $21.8 \%$ was checked by the owner and in $86.2 \%$ 
by the caregiver. On the subject of number of doses, in $78.4 \%$ was confirmed by the owner and in $100 \%$ by the caregiver. About cleaning, $37.8 \%$ cleaned the mouthpiece after each use. If they used inhaled corticosteroids: $71.4 \%$ used bronchodilator before inhaled corticosteroids in crises and $55.2 \%$ rinsed the mouth and washed face after inhaled corticosteroids. About $56.8 \%$ took DPIs to school and $66.7 \%$ to sports activities. There was statistically significance difference between those who cleaned their mouth after inhaled corticosteroid and the follow-up period: $33.3 \%$ were followed-up for less than two years and $70.6 \%$ for 2 years or more $(p=0.047)$. The other results comparing the 2 groups of follow-ups and those who had or not relatives with asthma had no statistically significant difference.

Table 3. Results from the observation of inhaler use technique of dry-powder inhalers.

\begin{tabular}{|c|c|c|c|c|c|c|c|}
\hline & \multirow[b]{2}{*}{$\begin{array}{l}\text { Total } \\
(n=37)\end{array}$} & \multicolumn{3}{|c|}{ Follow-up time } & \multicolumn{3}{|c|}{ Family member with asthma } \\
\hline & & $\begin{array}{l}<2 \text { years } \\
(n=19)\end{array}$ & $\begin{array}{l}>2 \text { years } \\
(n=18)\end{array}$ & $\begin{array}{l}\text { Chi-square/ } \\
\text { Fisher's } \\
\text { exact test }\end{array}$ & $\begin{array}{l}\text { Yes } \\
(n=13)\end{array}$ & $\begin{array}{l}\text { No } \\
(n=24)\end{array}$ & $\begin{array}{l}\text { Chi-square/ } \\
\text { Fisher's } \\
\text { exact test }\end{array}$ \\
\hline Prepare the dose & $94.6 \%$ & $100 \%$ & $88.9 \%$ & NA & $84.6 \%$ & $100 \%$ & NA \\
\hline Place the device correctly & $100 \%$ & $100 \%$ & $100 \%$ & NA & $100 \%$ & $100 \%$ & NA \\
\hline Child is standing or sitting & $100 \%$ & $100 \%$ & $100 \%$ & NA & $100 \%$ & $100 \%$ & NA \\
\hline Performs a forced expiration & $56.8 \%$ & $52.6 \%$ & $61.1 \%$ & $p=0.603$ & $61.5 \%$ & $54.2 \%$ & $p=0.666$ \\
\hline $\begin{array}{l}\text { Place the mouthpiece correctly } \\
\text { (between the teeth) }\end{array}$ & $97.3 \%$ & $100 \%$ & $94.4 \%$ & NA & $62.3 \%$ & $100 \%$ & NA \\
\hline Inhale deeply and quickly & $86.5 \%$ & $94.7 \%$ & $77.8 \%$ & $p=0.180^{f}$ & $84.6 \%$ & $87.5 \%$ & $p=1.000^{f}$ \\
\hline $\begin{array}{l}\text { Inspiratory pause of 5-10 } \\
\text { seconds }\end{array}$ & $75.7 \%$ & $78.9 \%$ & $72.2 \%$ & $p=0.714^{f}$ & $84.6 \%$ & $70.8 \%$ & $p=0.446^{f}$ \\
\hline Afterwards slowly expires & $67.6 \%$ & $68.4 \%$ & $66.7 \%$ & $p=0.909$ & $76.9 \%$ & $62.5 \%$ & $p=0.476^{f}$ \\
\hline $\begin{array}{l}\text { Wait } 30-60 \text { seconds for the } \\
\text { next inhalation }\end{array}$ & $64.9 \%$ & $57.9 \%$ & $72.2 \%$ & $p=0.362$ & $69.2 \%$ & $62.5 \%$ & $p=0.734^{f}$ \\
\hline
\end{tabular}

Legend: ${ }^{\mathrm{f}}$ - fisher's exact test, NA - non applicable.

Table 4. Other questions made to the group that used dry-powder inhalers.

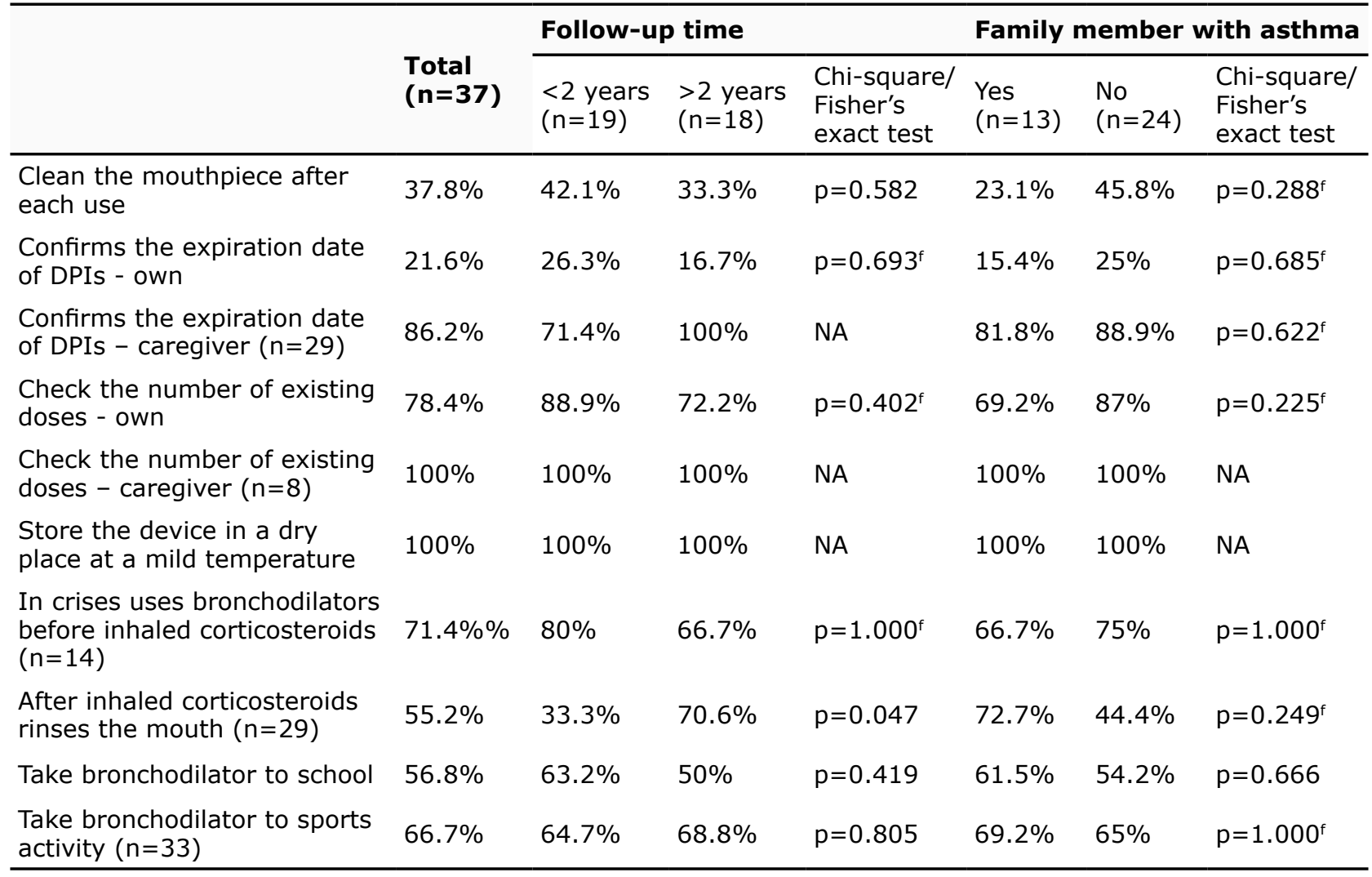

Legend: DPIs - dry-powder inhalers, ${ }^{\mathrm{f}}$ - fisher's exact test, NA - non applicable. 
Figure 2. Inhaler use technique in dry-powder inhalers users

No relatives with asthma $(n=24)$
Relatives with asthma $(n=13)$
Follow-up period $\geq 2$ years $(n=18)$
Follow-up period $<2$ years $(n=19)$
Total $(n=37)$

Correct Technique

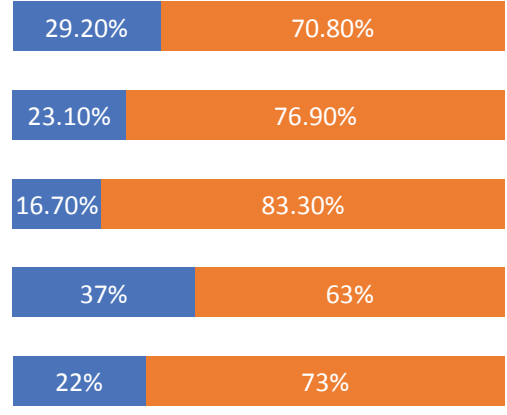

Incorrect Technique

\section{Discussion}

In our study just over half (54.3\%) of pMDIs with spacer and less than a third (27\%) of DPIs users performed a correct inhaler use technique with statistically significant difference. In several studies with children the percentage of correct inhaler use technique was: $47.1 \%-68.1 \%$ in pMDIs with spacers and $29 \%-34.6 \%$ in DPIs, therefore our study presented similar results. $6,7,8$ We assumed that the better results in children who used pMDIs with spacers rather than DPIs, were probably because the technique is simpler, done by the caregivers and doesn't need a forced expiration, deep and quick inspiration and an inspiratory pause. We consider that the percentage that correctly performs the technique in both type of devices is low. The most frequent errors described in literature for pMDIs with spacers users were:

- Not shaking the pMDIs (21\%-43.8\%). ${ }^{6,8,9}$

- Not breathing slowly (68.8\%). ${ }^{9}$

- Inhalation duration under 10 seconds (24.4\%-34\%)..$^{6,9}$ - Not waiting 30 seconds between inhalations (25.5$72.2 \%) .7,9$

In our study the most frequent mistake in pMDIs with spacers users not wasting a puff into the "air" in the first use or if not used for a long time (50\%), and not waiting 30 seconds between inhalations (28.3\%). This last result was similar to other studies. Other frequent mistakes described in literature were less frequent in our sample: not shaking the pMDIs $17.4 \%$, not breathing slowly 5\% and inhalation duration under 10 seconds $4.3 \%$.

The most frequent errors described in literature for DPIs users were:

- Not performing the first expiration (51.9\%). ${ }^{6}$

- Not performing a deep inspiration (24-51\%).8,10

- Not performing an inspiratory pause (32.6\%$54.3 \%){ }^{6,10}$

The most frequent mistakes in DPIs users found in our study were not performing the first expiration correctly $43.2 \%$, not performing an inspiratory pause $24.3 \%$, not expiring slowly afterwards $32.4 \%$ and not waiting 30 seconds between inhalations $35.1 \%$. The first two in a slightly lower percentage than verified in other studies; the last two were not evaluated in the other studies. Only $13.5 \%$ didn't do a deep and quick inspiration, a better result than found in literature.
Factors which may affect correct technique, in others studies, were younger patients, male gender, using an inhaler for more than a year, being taught by a trained technician, training and checking the technique repeatedly and the level of education of the caregivers. $6,7,8,10$ In our study we evaluated if correct technique was associated with follow-up period and family members with asthma but these showed no statically significant difference. Some studies have been made about using videos to teach inhaler use technique to children, with promising results. ${ }^{11,12}$

Regarding the additional questions, only about one third washed the spacer correctly and at the right frequency $(34.8 \%)$, cleaned the mask of spacer $(30.4 \%)$ and cleaned the mouthpiece of DPIs after each use (37.8\%). One study demonstrated that $46.7 \%$ cleaned spacers after each use. ${ }^{13}$ Other study verified that $63 \%$ cleaned the spacer more than four times in a month.14 Therefore, in our study, device cleaning percentages were lower, probably because it is a topic less frequently addressed in the appointment. This is a point to improve in our appointment, we must teach how to properly sanitize the devices, as well as check if they are damaged. In our study we didn't ask how long they had the spacer or how often they replaced it. In DPIs users, despite being older and autonomous, less than a fifth checked by themselves the expiry date. We should also empower adolescents in order to make them more responsible for managing their disease.

\section{Conclusion}

Multiple mistakes were made, even in users who had been followed up for several years. In DPIs users there was a higher percentage of mistakes. Some other mistakes were detected like not cleaning the device properly, not using bronchodilators before inhaled corticosteroids in crisis, not rinsing mouth after inhaled corticosteroids and not taking bronchodilators to school in crisis. Thus, the inhaler use technique must always be observed by the physician in all appointments, especially in DPIs users in which the correct use depends on their autonomy. Such observation will provide opportunity to physician to correct errors in inhaler in every appointment.

\section{Compliance with Ethical Standards}

Funding: None

Conflict of Interest: None 


\section{References:}

1. Global Initiative for Asthma. Global strategy for asthma management and prevention,2021.

2. Gillette C, Rockich-Winston N, Kuhn JBA, Flesher S, Shepherd M. Inhaler Technique in Children With Asthma: A Systematic Review. Acad Pediatr. 2016;16(7):605-15.

3. Aguiar R, Lopes A, Ornelas C, Ferreira R, Caiado J, Mendes $A$, et al. Terapêutica inalatória: Técnicas de inalação e dispositivos inalatórios. Rev Port Imunoalergologia. 2017;25 (1):9-26.

4. George F. Ensino e Avaliação da Técnica Inalatória na Asma. Orientação no 010/2017 de 26/06/2017:1-11.

5. Volerman A, Kan K, Carpenter D, Press VG. Strategies for improving inhalation technique in children: A narrative review. Patient Prefer Adherence. 2021;15:665-75.

6. Capanoglu M, Misirlioglu ED, Toyran M, Civelek E, Kocabas $\mathrm{CN}$. Evaluation of inhaler technique, adherence to therapy and their effect on disease control among children with asthma using metered dose or dry powder inhalers. J Asthma. 2015;52(8):838-45.

7. Deerojanawong J, Sakolnakorn VP, Prapphal N, Hanrutakorn C, Sritippayawan S. Evaluation of metered-dose inhaler administration technique among asthmatic children and their caregivers in Thailand. Asian Pacific J Allergy
Immunol. 2009;27(2-3):87-93.

8. Kamps AWA, Ewijk BV, Roorda RJ, Brand PLP. Poor inhalation technique, even after inhalation instructions, in children with asthma. Pediatr Pulmonol. 2000;29(1):39-42.

9. Samady W, Rodriguez VA, Gupta R, Palac H, Karamanis M, Press VG. Critical errors in inhaler technique among children hospitalized with asthma. J Hosp Med. 2019;14(6):361-5.

10. Alshehri M. Comparative study of different inhaler devices in asthmatic children. Ann Saudi Med. 2003;23(2):349-53.

11. Carpenter DM, Lee C, Blalock SJ, Weaver M, Reuland D, Coyne-Beasley $T$, et al. Using videos to teach children inhaler technique: A pilot randomized controlled trial. J Asthma. 2015;52(1):81-7.

12. Shaw N, Souëf PL, Turkovic L, McCahon L, Kicic A, Slys PD, et al. Pressurised metered dose inhaler-spacer technique in young children improves with video instruction. Eur J Pediatr [Internet]. 2016;175(7):1007-12.

13. Tay ET, Needleman JP, Avner JR. Nebulizer and spacer device maintenance in children with asthma. J Asthma. 2009;46(2):153-5.

14. Walia M, Paul L, Satyavani A, Lodha R, Kalaivani M, Kabra SK. Assessment of inhalation technique and determinants of incorrect performance among children with asthma. Pediatr Pulmonol. 2006;41(11):1082-7. 